\title{
Gymnastics as a Remedy: A Study of Nineteenth- Century Swedish Medical Gymnastics
}

\author{
By Pia Lundquist Wanneberg*
}

\begin{abstract}
This paper examined a form of 19th century globally spread physiotherapy known as Swedish medical gymnastics. The goal of the research was to determine the aim of medical gymnastics, its elements and its performance style. The study also investigated why medical gymnastics had such a large global impact? Applying a qualitative text analysis, the results showed that medical gymnastics, through individually tailored movements, aimed to restore health, which for various reasons had declined. Furthermore, the treatment made particular use of passive movements carried out by someone other than the patient. Even massage was included. However, there were also active movements, under the supervision of or supported by a gymnast. As for the global spread, two factors contributed to this: first, its scientific and philosophical foundations were typical of the period; and second, recent graduates of the Royal Central Gymnastics Institute in Stockholm went abroad to promote Ling gymnastics, the type of gymnastics to which medical gymnastics belonged. Medical gymnastics treatment became an important source of income for both the graduates and the Royal Central Gymnastics Institute. This led, ultimately, to many people coming into contact with this form of gymnastics. Yet another reason was its rootedness, both in the past and in the future, where physical exercise remains of major importance for maintaining or regaining health.
\end{abstract}

Keywords: Medical gymnastics, Ling gymnastics, qualitative text analyses, physiotherapy.

\section{Introduction}

Although physiotherapists are the third-largest group of healthcare professionals, after physicians and nurses, their early history has not been much researched. In the existing research, however, Per Henrik Ling's name appears remarkably often, as well as the form of gymnastics he established during the nineteenth century, known as Ling gymnastics or Swedish gymnastics (WikströmGrotell et al. 2013, Nicholls and Cheek 2006, Ottosson 2011). In this form of gymnastics, medical gymnastics was included and emerged as a major phenomenon not only in Sweden but also around the world (Ottosson 2011). However, research has shown (Ottosson 2005, Ottosson 2011) that the successes of medical gymnastics also led to criticism from physicians who regarded it as unscientific. Moreover, they considered themselves best suited to diagnose and treat illnesses with physiotherapy. These criticisms came primarily from physicians, particularly orthopaedists, at Karolinska Institutet (KI) - the awarder of the Nobel Prize in Physiology or Medicine. They believed that the practitioners of medical gymnastics - the gymnasts - were acting far too independently, i.e. without the support of physicians, and that their scientific claims were excessive. However, the Royal Central Gymnastics Institute (RCGI), the stronghold of Ling gymnastics, levelled criticism at the orthopaedists at KI, including the argument that they were performing medical gymnastics without having qualified at RCGI.

\footnotetext{
* Associate Professor, GIH, The Swedish School of Sport and Health Sciences, Sweden.
} 
The struggle between the factions for influence and the preferential right of interpretation was long and hard, culminating in medical gymnastics moving from RCGI to KI in 1934. The former gymnasts, now known as physiotherapists, thus came under the supervision of the physicians, which, among other things, led to their previously autonomous professional roles being diminished. Physiotherapy gradually went from being an independent, high-status profession to a more dependent occupation held in significantly lower esteem (Ottosson 2005, Ottosson 2011).

One explanation for transferring the medical training and the treatment of patients from RCGI to KI is that Ling gymnastics had over time come to stand on its own two feet. Research has shown that its followers considered it in a class of its own, and therefore superior to all other forms of physical exercise. In their view, it required no further development, thus causing it to stagnate (Lindroth 2004). Another explanation is that the rise of modern medicine during the second half of the $19^{\text {th }}$ century brought with it the vaccine and surgical treatment of illnesses, as well as the growth of hospitals, medical training, specialisation and medical research (Bliss 2011, Weisz 2003). In this area, Sweden followed larger Western developments, which, among other things, led to a form of medicine rooted in contemporary natural science gradually replacing traditional medicine during the $19^{\text {th }}$ century. Medical students now received a thorough education in physics, chemistry and biology. In addition, a clinical practice was developed that enabled the collection of data on the symptoms of illnesses, conditions and treatment outcomes, which far surpassed an individual physician's experiences and knowledge. Twentieth century modern medicine came to enjoy a position of power in much of the world, and in some places, including Sweden, it completely trumped all previous forms of medicine and treatment methods (Johannisson et al. 2010). Physicians were now the authority to whom people listened, and physiotherapy was consigned to the fringes of medical science. The $19^{\text {th }}$ century scientific claims made by its proponents at RCGI had been entirely rejected or considerably weakened (Ottosson 2011).

According to historian Anders Ottosson (2016), the early history of physiotherapy has been largely forgotten. Although physiotherapy has been practised in all eras and cultures, research tends to consider England the cradle of modern physiotherapy, following the formation of the English Chartered Society of Physiotherapy in 1894. Yet, its modern history did not begin then. This article aims to more closely examine the $19^{\text {th }}$ century prior to 1894 . Thus, the guiding research questions are: 1 . What was the aim of the medical gymnastics that formed part of Ling gymnastics? 2. What did it involve and how was it performed? 3. Why did it have such a large global impact?

First, the origins, establishment and aims of Ling gymnastics will be briefly described. Second, medical gymnastics and its aims and content will be examined. Finally, the paper will focus on the reasons for its success. 


\section{Ling Gymnastics: Sweden's Physical Cultural contribution to the World}

At the beginning of the $19^{\text {th }}$ century, different forms of kinetic culture were developed in Europe. This included a variety of activities, such as Swedish Ling gymnastics, German Turnen, and English sport. The newfound interest in physical activity arose for a number of reasons. Particularly significant were the new educational ideals of late $18^{\text {th }}$ century Enlightenment philosophy, including the ideals of equality stemming from the French Revolution, expanded citizenship training, and the need for physical strength prompted by the Napoleonic Wars. At the forefront of the new gymnastics was the philanthropic educational movement that emerged in Germany during the final decades of the $18^{\text {th }}$ century. In these special educational institutions, 'schools of philanthropy', physical exercise was given major prominence. Proponents believed that a humane education should draw attention to the body and mind. Physical exercise comprised a mixture of aristocratic forms on the one hand, such as fencing, horse riding and dance, and bourgeois or generally popular sporting activities, such as running, skating and hiking, on the other. Nevertheless, the exponents systematised, and where necessary created, movements and exercises, considered various programmes and methods, and reflected on specific physical effects. In 1793, the leading reformer Johann C. F. Guts Muths published his ideas in the influential Gymnastikfür die Jugend [Gymnastics for Youth], which has been translated into many languages (Lindroth 1994, Pfister 2003).

One person influenced by the new gymnastics was Per Henrik Ling (17761839), whose form of gymnastics has been described as one of Sweden's biggest cultural exports. In 1813, RCGI (today known as the Swedish School of Sport and Health Sciences) was founded with the aim of developing Ling gymnastics. RCGI started to send gymnasts abroad as early as the 1830s and by the turn of the $20^{\text {th }}$ century was enrolling foreign students and physicians in its courses. For example, during the 1880s RCGI received visitors from the neighbouring Nordic countries, as well as from Austria, Belgium, Chile, England, France, Germany, Greece, the Netherlands, Japan, Portugal, Romania, Russia, Switzerland, Turkey and the United States. By the beginning of the twentieth century, Ling gymnastics had become well known in many parts of the world and RCGI was a normative centre of such practice (Lindroth 1994, RCGI 1913).

With the aid of specially designed movements, Ling gymnastics aimed to exercise the body in as balanced and holistically harmonious way as possible, including the body's internal organs and inner soul. The idea of holistic harmony originated from Ling's understanding of the philosophy of nature, namely that everything was interconnected. As individuals consisted of a number of different parts, they could not be regarded as completely whole. Rather, wholeness was dependent on how the different parts related to each other. In short, it was thought that harmony led to good health, while disharmony created ill health. The link between physical exercise and science constituted one of the cornerstones of Ling gymnastics. For Ling, the legitimacy of the method was founded on every movement being based on contemporary knowledge of a person's anatomy and physiology. He divided his gymnastics into four elements: 
educational, military, medical and aesthetic. Educational gymnastics were the form conducted in schools. However, this came to be influenced by the more exercise- and fight-oriented content of military gymnastics, even though this had been originally intended for soldier training. For example, considerable space was given to fencing. Medical gymnastics were designed to cure or alleviate illnesses and physical suffering. It gave Ling gymnastics the medical and physiological features that also influenced educational gymnastics, e.g. the importance of posture. Finally, the aim of the aesthetic form was to express the internal, i.e. thoughts and feelings, through the external body. However, this form never made much of an impact, either at RCGI or elsewhere (Pfister 2003, Ottosson 2010, Meckbach and Lundquist Wanneberg 2011).

This article focuses on one particular element of Ling's system: medical gymnastics. RCGI graduates were schooled in educational, military and medical gymnastics and were therefore employable in three areas of society: the army, schools and the health sector. Whenever graduates left Sweden to promote Ling gymnastics abroad, which RCGI considered important, they were all trained in medical gymnastics. Initially, only men travelled in this capacity, but following the admission of female students to RCGI in 1864, women did as well. To carry out this missionary work, they required funds for living expenses, and so providing medical gymnastic treatment became a significant source of income. It transpired that this was so lucrative, several Swedish gymnasts opened clinics abroad, while others were employed by institutes and health resorts. Thus, they came to influence and inspire domestic physicians and laymen alike. Consequently, medical gymnastics spread to more or less all major European cities and health resorts, as well as further afield to places such as Russia and the United States. In addition to a modest government grant, medical gymnastics became an important source of income for RCGI, because in addition to educating students, it received patients for treatment (Ottosson 2005, 2011; WikströmGrotell et al. 2013).

One example of someone who travelled abroad was RCGI-educated Nils Posse. In 1889, he took up a teaching post at the Normal School of Gymnastics in Boston, USA, which in 1890 trained more than 200 budding Ling gymnastics teachers. That same year, he founded the Posse Gymnasium, which comprised three sections: one for teacher training, one that taught Ling gymnastics to men, women, and children, and one that taught medical gymnastics. Students were offered a two-year programme inspired by the one run by RCGI that included educational and medical gymnastics. After graduation, they also had the option of a further year of study. Graduates subsequently worked as school gymnastics teachers or within the field of medical gymnastics. In Boston, five hospitals established medical gymnastic clinics staffed by Posse Gymnasium alumni. However, Posse's influence was not restricted to Boston. By publishing a periodical about Ling gymnastics in general terms, and with a particular focus on medical gymnastics, he achieved a far greater reach. In addition, he wrote educational books, such as the Handbook of School-Gymnastics of the Swedish System, which ran through several editions (Kennard 1994). 
While engaged in school gymnastics, Posse also carved out a medical gymnastics career. As previously mentioned, the two elements of Ling's system were closely connected, not just for Posse but also for all the gymnasts who headed out into the world. These outbound gymnasts disseminated the notion prevalent at RCGI of the superiority of Ling gymnastics to other types of physical exercise, as well as the ability of medical gymnastics to cure almost all ailments (Kennard 1994, Ottosson 2010, Wikström-Grotell et al. 2013). Existing research on Swedish medical gymnastics focuses heavily on issues related to its creation, development and the involved parties, while its specific contents are less researched.

\section{Methodology}

The approach of this study is historical. As a historian you can't create your own data so you have to analyse the remnants that are available. In this case, I have examined the bequeathed writings of Per Henrik Ling and his successors in the field of medical gymnastics, Lars Gabriel Branting, Truls Johan Hartelius, Anders Wide and Johan Arvedson, as well as material from RCGI's archive (part of the Swedish National Archives). The books and the writers are more thoroughly described in the next section.

The methodology used was qualitative text analysis. By text analysis we mean a systematic quantitative or qualitative analysis of primary data collected from various types of texts (Denzin and Lincoln 2008). In this case, it is qualitative because conceptions, experiences, and ideas expressed in the assembled texts have been noted. Analysing qualitative data requires understanding of how to make sense of texts so that you can answer your research questions. In this case, the analysis has involved a careful reading and rereading of all the material to pin down the key themes of the texts in relation to the aim and research questions. In this process, texts patterns are studied by identifying the units of meaning in the form of conceptions and ideas. The patterns were then aggregated to larger elements, called themes (Cresswell, 2012).

To make sense of the findings, quality studies also require pre-existing understanding of the examined phenomenon; that's the key to comprehension and interpretation (Denzin and Lincoln 2008). In this instance, this requirement is satisfied by previous research in the field.

\section{Findings}

\section{Per Henrik Ling and medical gymnastics}

Ling left behind few gymnastic writings. The volume that most extensively examines his view of gymnastics is the posthumously compiled Gymnastikens allmännagrunder [The General Basis of Gymnastics]. In this, he sets out his perspective on the four elements of his system, as well as on health and illness. 
For Ling, health and a holistic view of the human being were connected; this view entailed all parts of the body and soul being in equilibrium, i.e. harmony, and illness was a disturbance or disharmony between them. According to Ling, the body without inner peace not only felt physically ill, but was also in conflict with its spiritual essence (Ling 1854).

Ling stated that human beings consisted of three basic forms: the mechanical, the chemical and the dynamic. The mechanical form comprised muscular strength. Gymnastics could influence this form, both preventively through educational gymnastics and by curing various illnesses through medical gymnastics and thus restoring the original harmony. Ling assigned people's external actions to the chemical form, especially eating foodstuffs and taking medicine, while spiritual or mental aspects were assigned to the dynamic form (Ling 1854).

Health required not only harmony in the relevant basic form but also between the forms. According to Ling, the three basic forms interacted within the organism in slightly different ways. First, none of them could be absent, otherwise the individual would cease to be whole, and second, the three had to be in balance. For instance, when combating an illness, one should determine the form that needed an increase, which always had to be balanced against the others. In this way, Ling viewed it as wrong to use gymnastics to treat a fevered person. The reason being that with a fever, the mechanical form was noticeably overburdened "by the blood's rapid circulation, the powerful movement of the respiratory organs or the violent shaking of all limbs" (Ling 1854:86). In this case, it was the chemical form that needed to be increased.

However, there were also situations where the chemical form could not be increased any further, thus requiring measures other than medicine, which, in Ling's view, was what physicians most often used to treat ill health. Nevertheless, Ling believed a physician ought to prescribe exercise or cultural recreation to patients if the mechanical or dynamic forms needed strengthening. Just as it would be wrong to order a healthy person to do nothing but eat and drink while never moving or doing recreational activities, it was equally wrong to only try to increase the chemical form when treating all illnesses (Ling 1854).

In other words, Ling was no advocate of medicine. He was not totally opposed to it, but he felt its medical element had become far too dominant at the expense of the mechanical, or iatromathematical, element. Rooted in the $16^{\text {th }}$ and $17^{\text {th }}$ centuries, iatromathematics was a school of thought that explained the anatomy and physiology of humans in mechanical, mathematical and geometric terms. Both healthy and sick bodies were regarded as living machines that, if required, could be restored through mechanical intervention. According to Ling, the chemical and mechanical approaches had created an imbalance, which made medicine incomplete. To remedy this, he wished to strengthen the body's mechanical element using carefully selected movements. He believed that only once the chemical and mechanical were in balance, could medicine achieve its full potential (Ling 1854, Ottosson 2005).

Fundamentally, the perception of treating illnesses with movements was that the outer affected the inner, i.e. outer mechanical movements affected the organism's interior. Ling's argument in this respect was also holistic: everything 
added to a body affected its whole being. Just as a chemical influence in the form of food affected the body's smallest parts, so did the mechanical influence. According to Ling, everything in an organism required a certain amount of space, and for a specific part, every change in the space also affected the adjoining part. Thus, the smallest change to the body's posture affected a nerve, vein, muscle or tendon, leading, in turn, to changes in the nearest parts, which spread like a domino effect. Ling also believed that the precise dose for a mechanical influence could be determined in exactly the same way as what influenced the chemical element. The amount of pressure applied would affect, for instance, a nerve differently. Weak pressure aggravated the nerve, stronger pressure hurt and even more pressure would numb (Ling 1854).

Also important to Ling was the relationship between active and passive movements. As mentioned, medical gymnastics aimed to alleviate or overcome various illnesses by way of the individual personally adopting suitable positions or performing effective movements. The forms of movement initiated by Ling were divided into active, passive and duplicated. Active movements were all those that presupposed the muscular activity of the person being treated. Passive movements were when one or more gymnasts performed a movement with a patient's body part without the latter helping or offering resistance; this included movements performed on the subject's body parts. Finally, duplicated movements were resistive movements that either the gymnast or the patient performed. According to Ling, passive movements were superior to active ones for treating an illness because the latter had ceased to positively affect the ill body. For someone with pathological abnormalities, their body parts were in disharmony and should be brought into harmony through external impulses in the form of thought-out passive movements (Ling 1854, Wide 1912).

According to Ling, the most common causes of illness could be traced to one of the basic forms, and it was there that measures should be taken. However, secondary conditions could manifest that had to be addressed before treating the primary disorder. One difficulty was that the symptom of an illness most often presented itself in a basic form other than the one where the cause lay. For example, Ling believed that rheumatic disorders were a chemical imbalance expressed mechanically through eye spasms and a numbed or paralysed arm, but when the person in question began to recover, the chemical form would emerge: a runny eye and a swollen arm (Ling 1854).

Ling also provided, to a certain extent, instructions on how treatment for different illnesses should be administered. However, these often have the character of examples rather than detailed instructions. The conditions he cites as requiring medical gymnastics are illnesses of the nervous system, the circulatory system, the secretion system (internal organs, namely the liver, kidneys and bladder), and the muscular system, as well as skin, febrile, and skeletal diseases. For example, liver disorders were to be treated using passive movements directed at the intestines, but above all, since liver problems resulted in an unusually high blood supply to the liver, it should be ensured that the circulation of blood was once again distributed evenly throughout the body. Circulation-boosting movements in the form of kneading and rolling were required for this purpose, 
i.e. the gymnast moved the patient's arms, legs, head, etc., in different circular movements. Subsequently, ever-stronger stimulating movements were to be performed on the patient's right-hand side while in a 'backward lying position' with their legs wide apart. Following this, the gymnast pressed the left-hand side of the loins upwards while the knees were held still and the right shoulder was stretched backwards (Ling 1854, Wide 1912).

In summary, Ling used medical gymnastics as a method for restoring health that had, for various reasons, declined or been lost entirely. As this condition was caused by a disorder of the bodily equilibrium, which he claimed denoted good health, and seeing that he recommended a more mechanical medicine, he developed restorative movements. Above all, he suggested a range of passive movements performed by a gymnast with or on the patient's body parts.

\section{Lars Gabriel Branting: The Successor}

The man who carried on Ling's medical gymnastic legacy was Lars Gabriel Branting (1799-1881), described as a marketing genius regarding Ling gymnastics in general and medical gymnastics in particular. Among other things, he had it recognised as medical science and convinced both the Swedish nobility and the medical academy that medical gymnastics could cure most illnesses from haemorrhoids to heart problems. It was during Branting's time as the RCGI director (1839-1862) that medical gymnastics won international recognition (Ottosson 2005).

In most cases, Branting was faithful to Ling. However, he systematised and concretised Ling's movements, and his posthumous writings provide insight into how medical gymnastics were performed. As already mentioned, RCGI accepted patients for treatment, which apparently was much sought after given that people queued up for it (Ottosson 2005). In addition, Branting kept statistics of who was treated and what treatment they received. Table 1 shows how many people were treated and what the treatment period was for every fifth year during Branting's time as director.

Table 1. Number of Men and Women who Received Medical Gymnastic Treatment at RCGI, 1840-1860

\begin{tabular}{|c|c|c|c|c|}
\hline Year & Men & Women & $\begin{array}{c}\text { Mean number of } \\
\text { treatment months } \\
\text { per person }\end{array}$ & $\begin{array}{c}\text { Mean number of } \\
\text { treatment hours } \\
\text { per person }\end{array}$ \\
\hline 1840 & 182 & 134 & 2 & 96 \\
\hline 1845 & 131 & 76 & 2 & 96 \\
\hline 1850 & 142 & 100 & 2 & 96 \\
\hline 1855 & 159 & 92 & 2 & 96 \\
\hline 1860 & 158 & 75 & 2 & 96 \\
\hline
\end{tabular}

Source: RCGI archive, H1:1

The table shows that between 207 and 316 people annually received treatment during the years in question and that even women were accepted, although the majority of patients were men. The average treatment time appears to have been 
the same across all years at 96 treatment hours over a two-month period. If these 96 hours were evenly distributed over the two months, this would mean ten to twelve hours per week, which must be seen as a lot by today's standards. What were the patients being treated for? And what effect did the treatments have? Table 2 provides an example of illnesses and outcomes for 1851.

Table 2. Cases of Illnesses that Received Medical Gymnastic Treatment at RCGI and their Outcomes in 1851

\begin{tabular}{|c|c|c|c|c|c|}
\hline Type of illness & Number & Cured & Improved & $\begin{array}{c}\text { Not } \\
\text { improved }\end{array}$ & $\begin{array}{c}\text { Treatment } \\
\text { discontinued }\end{array}$ \\
\hline Nerve & 32 & 7 & 22 & 0 & 3 \\
\hline Respiratory & 38 & 15 & 19 & 3 & 1 \\
\hline Vascular & 42 & 23 & 14 & 4 & 1 \\
\hline Lymphatic & 7 & 4 & 3 & 0 & 0 \\
\hline Anaemia & 10 & 5 & 5 & 0 & 0 \\
\hline Lower abdominal & 24 & 16 & 6 & 1 & 1 \\
\hline Urological & 15 & 9 & 6 & 0 & 0 \\
\hline Musculoskeletal & 21 & 6 & 11 & 4 & 0 \\
\hline Back & 18 & 11 & 6 & 0 & 1 \\
\hline Undefined & 54 & 30 & 20 & 2 & 2 \\
\hline
\end{tabular}

Source: RCGI archive, H1:1

The table shows that, according to Branting, not all patients were cured, but the majority were; furthermore, he noted improvement in most of those who went uncured. If we disregard the undefined category, the majority of people were treated for illnesses of the vascular system, respiratory organs and nerves. Nowadays, we would presumably refer to these as cardiovascular diseases, respiratory infections and mental illness, of which the first and third are common diseases in present-day Sweden.

The medical descriptions Branting drew up for his patients provide more information about illnesses and symptoms. So-called movement prescriptions were attached to these. In the medical descriptions, titles and ages are specified, while names are abbreviated, presumably an attempt at anonymisation. However, although Branting had placed tight restrictions on this material - it could not be read until 50 years after his death - it was probably still possible to work out who was who; this would have been problematic at the time as the patients included a number of prominent members of the nobility and upper classes (Ottosson 2005).

One example of a patient receiving treatment in 1859 is a 47 -year-old master carpenter, who had been suffering for two years from troublesome melancholy associated with insomnia, as well as an aversion to all work. Moreover, the patient was experiencing symptoms such as dizziness, buzzing and ringing in the ears, tingling wrists, tightness of the chest and shivering legs. His memory had also declined. According to Branting, the master carpenter was suffering from hypochondria. Following three months of medical gymnastic treatment, a month longer than the average, the man's mood had improved, and the dizziness and buzzing had ceased. However, he returned a couple of months later. The 
melancholy and aversion to all work had returned, and his heart felt heavy with worry, preventing him from lying on his left side. After a further month of medical gymnastics, Branting says he had made such an improvement that treatment at RCGI could stop (Branting 1882).

As Table 1 shows, RCGI received female patients as well. Another example from 1859 is 44-year-old Mrs Charlotta, who had been healthy during her childhood and adolescence. Her nerves, however, had become weak over the previous twelve to fifteen years due to several difficult childbirths. Four years earlier, she had suffered from severe cholera and had overused camphor, which left her enfeebled. She also had severe and heavy periods, which, apart from further weakening her, gave her headaches, made her nauseous and left her "nerves irritated." She had no appetite and was afflicted with excruciating pain during the morning, particularly in her shins and between her shoulders and was cold despite wearing wool as her base layer. In addition to this, she had a buzzing in her ears and a sour and disgusting taste in her mouth due to gastric acid (Branting 1882).

Branting did not make a definitive diagnosis, but Charlotta would probably have come under several of the categories of illness listed in Table 2. However, following two rounds of treatment with a one-month interval between them, Charlotta's condition improved considerably. According to Branting, she had fewer headaches; her vomiting ceased; her appetite improved, and her periods were not as heavy or painful. Moreover, the pain in her shins and between her shoulders disappeared, as did the buzzing in her ears. Even her gastric acid reflux was less bothersome (Branting 1882).

Children also received treatment at RCGI; for example, eight-year-old Henrik, who had been healthy for the first four years of his life but then succumbed to pneumonia. His right lung had been badly damaged, and Henrik was left with lasting symptoms, such as hoarseness, shortness of breath and a deformed thorax, which caused his left side to thrust forward and his shoulders to be significantly hunched. In the last few weeks before admission, he had experienced severe and prolonged sweating at night as well as "rattling" in his airways. He was hoarse and yawned frequently. He also had cold feet (Branting 1882).

In the spring of 1859 , Henrik, who probably falls into the respiratory illness category in Table 2, received medical gymnastic treatment as well as instruction in educational gymnastics. Together, they resulted in his shoulders being less hunched forward and his shortness of breath disappearing. He could even run without becoming breathless. Furthermore, the yawns, the throat clearing and the rattling all stopped, and his feet were once again warm. According to Branting's notes, Henrik had completely recovered (Branting 1882).

In summary, Branting systematised Ling's medical gymnastics and was heavily responsible for its geographic spread and reputation. At RCGI, he accepted patients, whether men, women or children, for treatments carefully adapted to individual needs, and the patients received treatment for virtually all the illnesses of that period. 


\section{The Successors}

Although Branting meticulously noted who received treatment, what they were suffering, and which treatment they received, the material is in part disorganised and unprinted. In addition, the handwritten prescriptions provide no detailed information about how the treatment was actually administered. The man responsible for compiling and systematising Branting's material was Truls Johan Hartelius (1818-1896), who in 1864 was appointed head teacher of the medical section at RCGI and remained in that post until 1887, making him the most prominent official representative of medical gymnastics after Branting. In 1870, he published Lärobokisjukgymnastik [Swedish Movements or Medical Gymnastics], primarily a compilation and clarification of Branting's notes and instructions. According to contemporary observers, the textbook (published in three editions) became the basis of future textbooks in the field (RCGI 1913).

The textbook clearly sets out the holistic perspective of medical gymnastics, as well as the fact that it was viewed as a remedy. Regarding the former, Hartelius believed that health and illness were not polar opposites. Humans were not either ill or healthy; rather, both conditions coexisted and could not be separated. Even when we perceived ourselves to be healthy, "the seeds of illness [could] be germinating within us," (Hartelius 1870:107) and there were parts that functioned well even during illness. According to Hartelius, health was therefore the normal functioning of those cells and tissues that made up organs controlling vital functions, such as breathing, digestion and circulation, whereas illness was due to cell, tissue or organ deviations or disruptions (Hartelius 1870).

How then could movements serve as a remedy? As Hartelius stated, active movements, such as floor gymnastics, led to increased heart activity, which accelerated blood flow and increased breathing. This in turn increased oxygenation. Passive movements also affected the blood flow, but without increasing heart activity. However, movements affected not only the heart and circulation but also all types of systems and organs. For example, they had positive effects on the nervous system, increased muscle tissue, affected digestion positively and offset constipation. Even abdominal organs were affected, which, according to Hartelius, meant that medical gymnastics had a good effect on menstrual disorders, urinary tract infections and kidney stones, to name but a few areas (Hartelius 1870).

The movements were grouped according to their strengthening, invigorating, calming, sleep-inducing, draining and evacuating effects. Draining movements referred to those used in cases of hyperaemia, a condition with higher-thanusual blood levels in tissue or organs, and evacuating movements were used for constipation. For example, a patient with anaemia would be treated using movements from several of these groups. According to Hartelius, seeing as anaemia by its very nature left the patient weak, strenuous movements could not be used; instead, the treatment should be restorative. The way that medical gymnastics produced improvement was primarily through its invigorating and strengthening movements. Although individually tailored, Hartelius believed the treatment had to take into account digestion, circulation and respiration. 
First of all, treatment was to include chest-expanding movements so that breathing became deeper and exhalations stronger. Thus, the blood was oxygenated and rid of carbon dioxide, which, according to him, accelerated the functions of the organs and boosted the metabolism. Second, since this illness was ordinarily associated with cold feet, the treatment would include draining movements designed to produce balanced circulation, thereby increasing the flow of blood to the feet. Third, to deal with poor appetite and digestion - also part of the clinical picture - movements affecting the stomach were to be included in the treatment, along with excretion-promoting movements. However, Hartelius also provides examples of conditions in which medical gymnastics had to play a more inconspicuous role. For instance, when suffering from chronic gastritis, adopting an appropriate diet was the most important measure: without this, medical gymnastics were ineffective. Still, it could help by way of movements affecting the abdominal muscles, the stomach and the intestines (Hartelius 1870, Wide 1912).

Another successor to Ling and Branting was RCGI-educated physician Anders Wide (1854-1938), also an ardent champion of medical gymnastics. For a period in the 1880 s, Hartelius employed him as a medical gymnastics teacher at RCGI, and in 1896 Wide published a medical gymnastics textbook intended for use in training gymnasts and physicians. The textbook (translated into English, German, French, Italian and Russian), which ran through at least three editions, is heavily based on the works of Ling and Branting, but is more detailed and accessible (Wide 1912).

As stated in this publication, a treatment would be performed as follows: the patient would arrive five to ten minutes prior to treatment so that they were not still breathless following their walk to RCGI. Each session's movements were put together in so-called day exercises, i.e. a treatment session involving systematically compiled movements and positions. Following each movement in the day exercise, the patient would rest for a few minutes so they could put enough energy into the next movement. It was important that the session was allocated in a reasonable amount of time - the treatment should not last less than an hour - and that it also took place between two mealtimes as neither a full nor an empty stomach positively affected the outcome. The surviving photographs show that patients were fully dressed during treatment, wearing a shirt, waistcoat, tie, trousers and shoes. Although, they may sometimes have removed their jackets. Women kept their dresses on. Following treatment at RCGI, otherwise known as home gymnastics, the patients also independently performed gymnastics since the movements sometimes needed to be done several times a day. Home gymnastics would be individually tailored and took into account the patient's age, general condition, occupation and living conditions (Wide 1912).

Let us look again at one of Branting's three patients above, Henrik. He was suffering complications following pneumonia that made him, among other things, breathless; he also had cold feet and a deformed thorax. Besides instruction in educational gymnastics, he might, too, have received a treatment similar to the one Wide recommended for chronic bronchitis: a day exercise that included 
sitting chest-lifting, half-lying foot rolling, foot flexion and extension, yard-sitting double arm-rolling, and arms lean-standing back-hacking. Sitting chest-lifting involved the patient resting their buttocks and upper legs on a horizontal surface while holding their knee and ankle joints at a right angle and their feet against the floor. The legs were held tightly while the arms were left hanging freely by the sides of the body. Standing behind the patient, the gymnast's body supported them so that their thorax was distended. The gymnast would then lift the patient's thorax upwards by placing their hands in the patient's armpits. This movement was, according to Wide, good for respiration (Wide 1912).

When performing half-lying foot rolling and foot flexion and extension, the patient would rest on a low plinth with a back support at an approximate 45degree angle. Foot rolling, considered particularly good for cold feet (which Henrik had), involved the gymnast taking hold of the foot with one hand and securing the lower leg with their other hand just above the ankle. The foot was then to be led through a conical movement. When doing flexion and extension, the patient would place their leg in the gymnast's lap, and the latter then took hold of it and stretched and bent the foot. For yard-sitting double arm-rolling, which was designed to improve circulation, the patient would sit with their arms stretched outwards while the gymnast stood behind them, providing support with their body and taking hold of the upper arms and rolling them in large circles for two or three minutes at the same rate as their breathing (Wide 1912).

When performing arms lean-standing back-hacking, the patient would be standing and grasping an apparatus a little in front of their body. The gymnast would stand behind them, hacking their back using the little-finger side of their hand, starting from the shoulders and going all the way down the back. Both hands would be used alternately. According to Wide, this exercise was beneficial for many things, including heart and lung problems (Wide 1912).

In summary, Hartelius and Wide, who both compiled, further systematised and clarified medical gymnastics, carried on the legacies of Ling and Branting. Their textbooks set out how the treatments were executed and which movements were to be used for different types of illnesses. Just like Ling and Branting, they considered these treatments a form of remedy.

\section{Swedish Massage}

The aforementioned described treatment of chronic bronchitis contains elements reminiscent of massage. Elements of massage are also found in Ling's description of passive movement, where the patient should be completely still while the gymnast not only performed movements with a body part but also manipulated it; this included beating, kneading, pounding and pressure. According to Wide (1912), there was, however, a desire among gymnasts and physicians to distinguish between medical gymnastics and massage in such a way that passive movements performed on patients would be classified as massage because no joint motion was performed together with or by the patient. Wide dismissed this view, while other physicians, including disciples of Ling and Branting, 
wished to distinguish between the two. One such physician was Johan Arvedson (1862-1936). In 1887, he founded something of an affiliate of RCGI, known as Arvedson's Gymnastic Institute, which until 1937 provided training in educational and medical gymnastics. Just like Wide, Arvedson wrote medical gymnastics textbooks, which also included massage. Interestingly enough, he referred to this form as Swedish massage, a term still used today. His books (translated into English) ran through multiple editions and were used for teaching, both domestically and internationally (Arvedson 1913, Wenham 1999).

According to Arvedson, medical gymnastics had included massage ever since its creation by Ling. However, he felt there were both theoretical and practical benefits to be gained from distinguishing between their respective techniques and effects. Arvedson defined massage as "a handling of the soft tissues by movable pressure in the form of stroking, rubbing, pinching or kneading, as well as striking and beating performed with a therapeutic aim." Meanwhile, medical gymnastics were "the treatment of a patient while exercising musculoskeletal organs" (Arvedson 1913:1).

Somewhat simplified, medical gymnastics comprised movements and positions, whereas massage involved four main kinds of strokes: effleurage, friction, petrissage and tapotement. Effleurage involved strokes directed towards the heart. The aim was to increase circulation as well as to press the tissue juice into the lymph vessels to enhance their circulation. In the first instance, strokes were to be light, long $(15-25 \mathrm{~cm})$ and relatively quick. In the second instance, they were also to be long and performed slowly, but the pressure was to be greater. According to Arvedson (1913), this stroke was good for swelling and oedema. However, it could also be performed as an initial massage in order to lessen tension and pain in the 'sick spot' and to counteract and reduce inflammatory changes, improve metabolism and help tired muscles.

According to Arvedson (1913), frictions - designed to break down and remove pleural thickenings and inflammatory products - involved the circular or rectilinear rubbing of any body part against a fixed surface. This rubbing was generally done using relatively strong pressure; however, the gymnast would also pay attention to the patient's reaction to any pain. Petrissage might, moreover, cause pain since it involved pinching and kneading so as to push up the tissues, normally the skin and the muscles. The easiest way to achieve this was to lift up with both hands a fold of skin or skin with underlying muscle and then rub it in the same way as clothes are hand-washed. This stroke had a similar effect to that of friction, i.e. they broke down pleural thickenings and inflammatory products.

The fourth stroke, tapotement, included techniques similar to striking and prodding, such as hacking, beating, pounding, shaking and vibration. Hacking is described above (arms lean-standing back-hacking), and the gymnast performed the beating using the palm of their hand, which was not to be tensed but should be soft and relaxed so that the treatment was not painful. With a loose fist, the gymnast should also pound in a relaxed way. With each strike, the gymnast was to press their hand into the flesh for a period of time so the hand went in as deep as possible. Shaking involved the relevant body part being grasped and 
moved from side to side, and the gymnast usually performed the vibrations using an electric vibrator that emitted small, fine vibrations. The gymnast performed gentle tapotement to stimulate tissue and cells, while more vigorous forms of this stroke dilated blood vessels, among other things (Arvedson 1913).

Arvedson highlighted throat, abdominal and general massage as particularly important forms of treatment. Throat massage consisted of effleurage, i.e. stroking. The patient would be seated leaning backwards on a chair with their throat and shoulders bare while the gymnast would stand behind them so that the front part of the throat was relaxed. The gymnast would hold their hands in such a way that the tips of their little fingers were touching each other at the tip of the chin, and the rest of their fingers were against the edge of the lower jaw. Their hands, pressing lightly and evenly, would then move down towards the clavicles. At this point, the hands would be turned so that the palms were facing down and the index fingers were pressed along the clavicles. This form of treatment was applied to increase circulation in the neck veins and was therefore deemed suitable for catarrh of the pharynx and trachea mucosa, brain "engorgement" and hastening the healing process after head trauma (Arvedson 1913).

Two strokes were primarily used for abdominal massage: kneading and friction. The former involved the flexible part of the abdomen being pressed from side to side and the latter the front abdominal wall being pushed down so deeply that the bowels "were squeezed between the front and rear abdominal wall" (Arvedson 1913:22). They were then treated using small fingertip frictions, thus enabling the treatment of accessible parts of the colon. According to Arvedson, abdominal massage had multiple positive effects, including improved digestion as a result of powerful kneading, while frictions made excretion easier and helped to resolve intestinal inflammation.

Finally, according to Arvedson, general massage invigorated and increased the body's metabolism while also alleviating insomnia. The patient was to lie in their bed or on a chaise lounge completely naked, covered by a blanket. The masseuse, who also performed the strokes, began the approximately one-hour massage by lifting the chest. The actual massage would then begin with the feet and lower leg effleuraged. The strokes were to be long and light, and then followed by kneading, hacking and patting the foot as well as passive foot rolling. After this, the gymnast was to perform the same massage on the lower and upper leg. Subsequently, what I would describe as medical gymnastic movements were performed on the knee and hip joints, including knee flexion and extension as well as pulling up and stretching the leg, followed by the same procedure on the other leg. The hands, arms, finger joints, wrists and shoulder blades would then be treated in the same way by what could be described as a mixture of massage and medical gymnastics. Then the back would be treated; this would involve kneading, hacking and beating. The gymnast would apply considerable pressure to the hips and shoulders and conclude the treatment with a thorough abdominal massage (Arvedson 1913).

In summary, Swedish massage was integrated into medical gymnastics for a long period of time. During Ling's and Branting's era, it was included as part 
of the passive movements. However, towards the end of the $19^{\text {th }}$ century, the two came to be increasingly distinct from one another in that medical gymnastics consisted of active movements performed by the patient and passive movements with their body parts, while massage consisted only of passive movements, primarily in the form of manipulating the patient's skin.

\section{Discussion}

This article has examined medical gymnastics, which formed part of Swedish Ling gymnastics, to identify what it was, how it was performed and how it could have such a big impact. Analogous with its founder Per Henrik Ling's natural philosophical understanding that everything was connected in harmonious wholeness, the aim of medical gymnastics was to restore bodily wholeness in order to achieve good health. Based on contemporary knowledge of human anatomy and physiology, Ling designed movements to do just this. As part of this treatment, he was fond of using passive movements, i.e. movements performed by someone other than the patient. Nowadays, this person might be a physiotherapist, chiropractor or masseuse, but at the time, he, or from 1864 also she, was known as a gymnast. However, active movements were also executed when the patient performed specific movements either under the supervision of, or with support from, a gymnast.

Mid $19^{\text {th }}$ century treatment would involve the patient - whether man, woman or child - describing their problems, whereupon the gymnast would prepare a programme of suitable movements, known as a prescription, which would be repeated if necessary. The $19^{\text {th }}$ century saw no distinction made between medical gymnastics and massage; however, around the turn of the century, they became discernible, with the former based on Ling's active and passive movements performed by a gymnast with the patient's body parts. Massage, on the other hand, consisted of passive movements performed by manipulating the patient's body parts.

Medical gymnastics achieved a major breakthrough in the Western world during the second half of the $19^{\text {th }}$ century. One reason was its natural philosophical framework, which strongly influenced natural science and academia during the early years of the $19^{\text {th }}$ century, and its scientific claims were typical of the era (Ottosson 2005). Another reason was the missionary aspect of Ling gymnastics, resulting in recent graduates going out into the world to spread the word, and a third was the financial value of the medical element in particular. Individual gymnasts and RCGI took on paying patients in order to finance their activities and means of living. Consequently, the reputation of medical gymnastics' curative ability spread. It is interesting that until the 1930s, the training and professional practice of medical gymnastics lay outside what is now regarded as traditional medicine. However, this changed when it was absorbed by modern medical science and downgraded to a type of assistant role to the medical profession. From having acted independently and with great authority, 
the practitioners were stripped of their responsibility for making diagnoses and designing suitable treatment programmes.

A fourth reason for the success of medical gymnastics was that its movements were rooted in the past but also in the future. Today, arguments at least as strong as Ling's and Branting's are advanced for the importance of movement for not only maintaining but also regaining our health. If we consider the importance of movement from a long-term historical perspective, Swedish medical gymnastics are clearly part of a long tradition. Evidence shows that as early as the prehistoric Chinese, Indian and African cultures, among others, bodily movements were deemed important to health and wellbeing. A well-known example is the Indian Vedic scriptures, written in around 1500 BC, which include preventive yoga exercises. From a Western perspective, ancient Greece represents the cradle of the concept, where physical activity and medicine were closely connected: physical exercise, along with good food and sleep, contributed to improved or retained health. During the Renaissance, when Europe's gaze was drawn again to Greek culture, the importance of physical activity was also identified. Books praising physical exercise and describing its effect on the body and mind were published in $16^{\text {th }}$ century Spain and Italy, and likewise in $18^{\text {th }}$ century England. And in the nineteenth century, the ideas reached the United States, which also imported European gymnastics systems that promoted physical exercise, including Ling gymnastics and German Turnen (U.S. Department of Health and Human Services 1999).

There is also evidence that the connection between physical inactivity and illness was identified in $16^{\text {th }}$ century Europe. Observations, recorded in book form, had been made that sedentary people appeared to be affected by more illnesses than active people. Physicians also linked sedentary occupations, such as cobbler or tailor, to particular illnesses and ill health. For example, at the beginning of the $18^{\text {th }}$ century, the Italian physician Bernardino Ramazzini encouraged these occupational groups to at least perform physical exercises on their days off (U.S. Department of Health and Human Services 1999).

As demonstrated, $19^{\text {th }}$ century medical gymnastics placed great faith in the effects that movements had on health and illnesses, and we can note that modern research has proven its champions right. There is now strong evidence that physical activity improves both mental and physical health and can prevent and treat illnesses in people of all ages. Physical activity and training can, as Ling argued, affect most organs and tissues, both when performed and over a longer period of time. We know, too, that the extent of the positive effect depends on the type and amount of physical activity, which Ling also claimed. Even the prescription of physical movement Ling believed physicians should issue and those Branting began to write have made a return in the Western world: patients can now be given physical activity or training as treatment - as a replacement for or a complement to medicine - on prescription (Kallings et al 2009). However, Ling gymnasts did not consider training relevant, which it later became with the $20^{\text {th }}$ century development of modern occupational physiology (Lundquist Wanneberg 2004). Nevertheless, gymnastics and movements were obviously seen as a remedy. 


\section{Conclusions}

The findings reached through this study show that the aim of medical gymnastics was to restore health that for some reasons had failed or declined. To treat these patients, passive movements were used, i.e. when one or more gymnasts performed a movement with the patient's body parts without the latter helping or offering resistance. However, active movements were also done by patients when supervised and supported by a gymnast. Even the socalled Swedish massage was integrated into medical gymnastics for a long period of time.

Medical gymnastics spread worldwide. Two factors contributed to this: first, its scientific and philosophical foundations were typical of the period; and second, recent graduates of RCGI in Stockholm went abroad to promote Ling gymnastics. Medical gymnastics treatment became an important source of income for graduates, several Swedish gymnasts who opened clinics abroad or were employed by institutes and health resorts, and for RCGI who accepted patients for treatment. Consequently, medical gymnastics spread to more or less all major European cities and health resorts, as well as further afield to places such as Russia and the United States.

Yet another reason was its rootedness both in the past and in the future, where physical exercise remains of major importance for maintaining or even regaining our health. Today, arguments at least as strong as the $19^{\text {th }}$ century medical gymnasts are expressed for the importance of movement.

\section{References}

Arvedson J (1913) Den svenska sjukgymnastikens och massagens teknik, verkningar och användning [The Technique, Effects and Uses of Swedish Medical Gymnastics and Massage]. Stockholm: A.B. Nordiska bokhandeln.

Bliss M (2011) The Making of Modern Medicine: Turning Points in the Treatment of Disease. Chicago: University of Chicago Press.

Branting LG (1882) Delar af L.G. Brantings efterlemnade handskrifter utg. enligt hans förordnandeaf Hjalmar Ling [Parts of L.G. Branting's Posthumous Writings: Published in accordance with His Provision by Hjalmar Ling]. Uppsala: C. E. Fritzes.

Cresswell JW (2012) Educational Research. Planning, Conducting, and Evaluation. Quantitative and Qualitative Research, $4^{\text {th }}$ ed. Upper Saddle River, N.J.: Pearson Merrill Prentice Hall.

Denzin N, Lincoln Y (2008) Collecting and Interpreting Qualitative Materials $3^{\text {rd }}$ ed. Thousand Oaks, Calif: Sage Publications.

Hartelius TJ (1870) Lärobok i sjukgymnastik [Swedish Movements or Medical Gymnastics] $1^{\text {st }}$ ed. Stockholm: Albert Bonniers boktryckeri.

Johannisson K, Nilsson I, Qvarsell R (2010) Medicinen blir till vetenskap: Karolinska Institutet under tvåårhundraden [Medicine Becomes a Science: Two Hundred Years of Karolinska Institutet]. Stockholm:Karolinska Institutet University Press.

Kallings LV et al (2009) Beneficial Effects of Individualized Physical Activity on Prescription on BodyComposition and Cardiometabolic Risk Factors: Results 
from a Randomized Controlled Trial. European Journal of Cardiovascular Prevention and Rehabilitation 16(1): 80-84.

Kennard JA (1994) The Posse Gymnasium. Journal of Physical Education, Recreation \& Dance 65(3): 50-52.

Lindroth J (1994) The History of Ling Gymnastics in Sweden: A Research Survey. Stadion 29(20): 164-177.

Lindroth J (2004) Ling - från storhet till upplösning: Studier $i$ svensk gymnastik 18001950 [Ling - From Greatness to Dissolution: Studies of the History of Swedish Gymnastics, 1800-1950] Stockholm: Symposion.

Ling PH (1854) Gymnastikens allmänna grunder [The General Basis of Gymnastics]. Uppsala: Palmblad \& Comp.

Lundquist Wanneberg P (2004) Kroppens medborgarfostran: Kropp, klass och genus $i$ Skolansfysiskafostran 1919-1962 [Civic Education: Body, Class and Gender in Physical Education, 1919-1962]. PhD diss., Stockholm University.

Meckbach J \& Lundquist Wanneberg P (2011) The World Gymnaestrada - a NonCompetitive Event: The Concept 'Gymnastics for All' from the Perspective of Ling Gymnastics. Scandinavian Sport Studies Forum. Retrieved from http://bit.ly/2Aj 9tMU [Accessed 11 September 2017].

Nicholls DA \& Cheek J (2006) Physiotherapy and the Shadow of Prostitution: The Society of Trained Masseuse and the Massage Scandals of 1894, Social Science \& Medicine. 62(4): 2336-2348.

Ottosson A (2005) Sjukgymnasten - vart tog han vägen? En undersökning av sjukgymnastyrkets maskuliniering och avmaskulinisering 1813-1934 [The Physiotherapist - What Happened to Him? A Study of the Masculinization and De-masculinization of the Physiotherapy Profession, 1813-1934]. PhD diss., Göteborg: Gothenburg University.

Ottosson A (2010) The First Historical Movements of Kinesiology: Scientification in the Borderline between Physical Culture and Medicine around 1850. The International Journal of the History of Sport 27(11): 1899-1919.

Ottosson A (2011) The Manipulated History of Manipulations of Spines and Joints? Rethinking Orthopedic Medicine Through the 19th Century Discourse of European Mechanical Medicine. Medicine Studies 3(2): 83-116.

Ottosson A (2016) One History or Many Herstories? Gender Politics and the History of Physiotherapy's Origins in the Nineteenth and Early Twentieth Century. Women's History Review 25(2): 296-319.

Pfister G (2003) Cultural Confrontations: German Turnen, Swedish Gymnastics and English Sport: European Diversity in Physical Activities from a Historical Perspective. Culture, Sport, Society 6(1): 61-91.

RCGI (1913).Kungl. Gymnastiska CentralInstitutets Historia 1813-1913 [The History of the Royal Central Gymnastics Institute, 1813-1913]. Stockholm: P.A. Norstedt \& Söner.

U.S. Department of Health and Human Services (1999) Physical Activity and Health: A Report of the Surgeon General Executive Summary, Chapter II. Retrieved from https://www.cdc.gov/nccdphp/sgr/pdf/sgrfull.pdf. [Accessed 11 September 2017].

Weisz G (2003) The Emergence of Medical Specialization in the Nineteenth Century. Bulletin of the History of Medicine 77(3): 536-574.

Wenham A (1999) The Role of Dr Johan Arvedson (1862-1936) in the Emergence and Development of Physiotherapy. Adler Museum Bulletin Volume 25(3).

Wide A (1912) Handbok i medicinsk och ortopedisk gymnastik [Handbookof Medical and Orthopaedic Gymnastics]. Stockholm: P. A. Norstedt \& Söners förlag. 
Wikström-Grotell C et al (2013) From Ling to the Academic Era: An Analysis of the History of Ideas in PT from a Nordic Perspective. European Journal of Physiotherapy, 15(4): 168-180. 